\title{
COMPARATIVE STUDY ON CLINICAL EFFICACY AND SAFETY OF FORMULATED AND MARKETED MYRRH EXTRACT IN CAPSULES
}

\author{
MOHAMED DAWOUD ${ }^{1,2 *}$, RANDA ABDOU ${ }^{3,4}$ \\ ${ }^{1}$ Department of Pharmaceutics, Faculty of Pharmacy, Umm Al Qura University, Holy Makkah, KSA. ${ }^{2}$ Department of Pharmaceutics and \\ Industrial Pharmacy, Faculty of Pharmacy, Helwan-University, Cairo, Egypt. ${ }^{3}$ Department of Pharmacognosy, Faculty of Pharmacy, \\ Umm Al Qura University, Holy Makkah, KSA. ${ }^{4}$ Department of Pharmacognosy, Faculty of Pharmacy, Helwan University, Cairo, Egypt. \\ Email: mohameddawoud3@yahoo.com
}

Received: 05 November 2019, Revised and Accepted: 22 November 2019

\begin{abstract}
Objective: The development of myrrh extract from natural origin capable of eradicating schistosomal infection has gained the interest of many scientists. Recently, myrrh extract is considered as the drug of choice from natural origin used to treat schistosomiasis. This study was performed to evaluate the safety and efficacy of hard gelatin capsules of myrrh extract in the treatment of Schistosoma mansoni compared to Mirazid which is the only herbal drug present in the market.
\end{abstract}

Methods: In the present study, the clinical evaluation of different doses of formulated myrrh extract hard gelatin capsules against different grades of S. mansoni infections (mild, moderate, and heavy) was carried out and compared with marketed soft gelatin capsules Mirazid.

Results: In all types of S. mansoni infection, it was clear that the efficacy of n-hexane and alcohol myrrh extracts hard gelatin capsules was higher than or equal to that of Mirazid soft gelatin capsules.

Conclusion: Hard gelatin capsules of myrrh extract (mixed doses) are more effective and more economic as a pharmaceutical dosage form for pharmaceutical manufacturers than Mirazid soft gelatin capsules. Consequently, with its lower price, it can reach the poor patient which is the main patient of schistosomiasis.

Keywords: Commiphora molmol, Schistosomiasis, Clinical investigation, Mirazid.

(C) 2020 The Authors. Published by Innovare Academic Sciences Pvt Ltd. This is an open access article under the CC BY license (http://creativecommons. org/licenses/by/4. 0/) DOI: http://dx.doi.org/10.22159/ajpcr.2020.v13i1.36277

\section{INTRODUCTION}

Human schistosomiasis is a widely spreading tropical infection. It causes complicated diseases with widely different symptoms [1]. In developing countries, it is considered as the second most prevalent disease after malaria that tremendously affects the social and economic development of these countries [2]. Based on the latest reports, about 652 million people live in Africa at risk of infection and 193 million people are already infected with schistosomiasis [3]. According to the previous studies, many patients are suffering from severe diseases as a result of their infection [4].

Schistosoma mansoni infection is widely spreading in about 53 countries, especially in the Nile valley neighbors, Sudan and Egypt, as well as in the new world, including Brazil, Surinam, Venezuela, and seven islands in the Caribbean [2-4].

Infection with $S$. mansoni has been reported to cause diarrhea in 0.78 million individuals, bloody stool in 4.4 million, and hepatomegaly in 8.5 million [5]. According to records made by ancient Egyptians, schistosomiasis occurred in the Nile Basin valley since remote times. Symptoms recorded in four papyrus papers dating back to 19501900 BC include hematuria with urinary bladder disturbances. In addition, schistosoma ova were discovered by Canadian scholars in a cirrhotic liver of a mummy from $1200 \mathrm{BC}$ [6]. The development of a myrrh extract from natural origin capable of eradicating schistosomal infection has gained the attention of many scientists. Many synthetic compounds such as organic antimony, nitrothiazole, oxamniquine, and praziquantel were currently used for the treatment of schistosomiasis. Although they have been used long ago, they have many undesirable side effects. Praziquantel is involved carcinogenesis associated with schistosomiasis by modulating enzymes involved in detoxification and protein metabolism [7]. Furthermore, the carcinogenic and genotoxic effects of praziquantel were reported in the Syrian hamster embryo cell transformation assay [8] and it was also considered as a potential mutagen similar to environmental arsenic [9-11].

Further studies revealed a lethal effect for the coadministration of oxamniquine and praziquantel at large doses to experimental animals $[12,13]$. The bioavailability, side effects, and toxicity of praziquantel are increased in the presence of liver disease [14]. Recently, myrrh extract obtained from natural origin is considered as the drug of choice for the treatment of schistosomiasis that does not show the side effects reported for praziquantel. Experimental and clinical studies proved that myrrh extract obtained from oleogum resin of Commiphora molmol is a safe, potent, economic, and antibilharzial agent. In addition, C. molmol (Myrrh) showed no clastogenic effect, no mutagenicity and was found to have anticarcinogenic effect [15]. Experimental studies on albino rats revealed no chromosomal aberrations, no fetal abnormalities, safety for liver and kidney, hematopoietic system, chromosomes, and fetal skeleton $[16,17]$.

The main objective of this work was to formulate the extract in hard gelatin capsules as an alternative pharmaceutical dosage form that is less costly and does need high technology compared to soft gelatin capsules "Mirazid ${ }^{\circledR}$ " marketed in Egypt. In addition, clinical investigation of the effectiveness of selected myrrh extract formulations in hard gelatin capsules was carried out in comparison to the soft gelatin capsules “Mirazid ${ }^{\circledR}$." 


\section{MATERIALS AND METHODS}

\section{Materials}

Myrrh purchased from France (Ethiopian origin), n-hexane was from Labscan Limited, Ireland, ethyl alcohol 96\% was from Scharlau Chemie S. A., Spain, lactose anhydrous was supplied by Egyptian Company for Pharmaceutical and Chemical Industries, and hard gelatin capsules shell No. 0 was supplied by Jedco International Pharmaceuticals Company.

\section{Methods}

Preparation of hard gelatin capsules containing myrrh extract

Myrrh extract was prepared by the maceration method as described before [18]. Five kilograms of myrrh were soaked in a glass container with n-hexane as a solvent at room temperature. The obtained extract was evaporated under vacuum at about $40^{\circ} \mathrm{C}$ (Buchi EL 131 Rotavapor, Germany). This process is continued until the $\mathrm{n}$-hexane solvent became colorless. N-hexane extract was concentrated under vacuum at about $40^{\circ} \mathrm{C}$ until it gave a thick brown sticky extract (n-hexane extract). The residue after extraction with n-hexane was soaked again in ethyl alcohol (96\%). The obtained alcoholic extract was evaporated under vacuum at about $50^{\circ} \mathrm{C}$. Alcohol was returned to the vessel and the process was continued until ethyl alcohol in the vessel was colorless. The ethyl alcohol extract was concentrated under vacuum at about $50^{\circ} \mathrm{C}$ and airdried until it gave a yellowish-brown fine powder (alcohol extract).

Table 1 shows six formulae of hard gelatin capsules. Hard capsules containing different doses of myrrh extract and different amounts of lactose anhydrous as a filler were formulated [18]. The ingredients were thoroughly mixed in a mortar. The blend powder was filled in hard gelatin capsules of size 0 ; each capsule contained $500 \mathrm{mg}$. The alcoholic extract was directly filled in capsules without excipients. Hard-shell capsules were filled using automatic capsule filling machine.

\section{Clinical evaluation of myrrh extracts hard gelatin capsules Design of study protocol}

The study was approved by the University Protection of Human Subjects Committee, and the protocol complies with the declarations of Helsinki and Tokyo for humans. This study was conducted at Ezbat Amleet, Etay-Elbarood Center; El-Behera Governorate. The results of a survey conducted in Behera Governorate showed that the prevalence of S. mansoni infection was $24 \%$ [19]. All the attendants of our clinical and parasitological evaluation were chosen randomly and screened for active S. mansoni by stool analysis by Kato-Katz method [20] and treated by formulated myrrh extract capsules after taking a written consent.

Cases were classified into three categories and 12 groups. Each group included 20 cases. The first category contained four groups having mild S. mansoni infection, the second included four groups having moderate S. mansoni infection, and the third consisted of four groups having heavy $S$. mansoni infection.

The four groups of each category were treated by one of the formulated myrrh extract hard gelatin capsules according to the following order:

Section I:

1. n-Hexane myrrh extract capsules $100 \mathrm{mg}$ and alcohol myrrh extract capsules $100 \mathrm{mg}$ (Formulae 1 and 4)

2. n-Hexane myrrh extract capsules $150 \mathrm{mg}$ and alcohol myrrh extract capsules $150 \mathrm{mg}$ (Formulae 2 and 5)

\section{Table 1: Formulations of myrrh extract hard gelatin capsules}

\begin{tabular}{lllllll}
\hline Ingredients (mg) & F1 & F2 & F3 & F4 & F5 & F6 \\
\hline N-hexane extract & 100 & 150 & 200 & - & - & - \\
Alcohol extract & - & - & - & 100 & 150 & 200 \\
Lactose anhydrous & 395 & 345 & 295 & - & - & - \\
Talc powder (lubricant) & 5 & 5 & 5 & - & - & - \\
\hline
\end{tabular}

3. n-Hexane myrrh extract capsules $200 \mathrm{mg}$ and alcohol myrrh extract capsules $200 \mathrm{mg}$ (Formulae 3 and 6).

Section II:

The fourth group treated by marketed soft gelatin capsules (Mirazid ${ }^{\circledR}$ $300 \mathrm{mg}$ ).

\section{Exclusion criteria}

Patients presented with any of the following signs were not excluded from the study:

1. Patients who gave a history of prior treatment with any antibilharzial therapy, for example, praziquantel, during the past 3 months

2. Patients with decompensate liver disease

3. Pregnant or lactating females

4. Treatment with any investigational drug in the past 4 weeks before the study entry

5. History of drug or alcohol abuse

6. Mental conditions rendering the patient unable to understand the nature, scope, and possible consequences of participating in the study

7. Patients unlikely to comply with the protocol, for example, uncooperative attitude, inability to return for follow-up visits, and likelihood of not completing the study according to the protocol.

\section{Treatment}

All cases were treated with two capsules from the designed dose $1 \mathrm{~h}$ before breakfast for 3 consecutive days. Thorough clinical examination, full history records and a clinical sheet were made for each case.

\section{Follow-up study}

Follow-up of cases which received treatment was done clinically and parasitologically by stool analysis using the Kato-Katz method after 1 , 2 , and 36 months of treatment and any new symptom was considered as a side effect. Data entry processing analysis was done using Chicago, SPSS Inc, USA. Chi-square test for significance was used to compare between different groups and t-test was used to compare between means.

\section{RESULTS AND DISCUSSION}

Schistosomiasis is still a public health problem in many regions, including Africa, the Middle East, Asia, and America. S. mansoni infection occurs in 53 countries ranging from the Arabian Peninsula, numerous countries in the African continent, particularly the Nile valley neighbors, Sudan and Egypt, to the new world, Brazil, Surinam, Venezuela, and seven islands in the Caribbean.

Schistosomiasis is estimated to infect 200 million people, with an estimated population of about 600 million at risk of infection. We choose Ezbat Amleet, Etay-Elbarood Center, Behera Governorate, to conduct this study as the prevalence of S. mansoni was $24 \%$ in Behera Governorate [19].

The extraction of myrrh was done by the maceration method according to our previous findings [18] which illustrated the high antibilharzial activity of these extracts in comparison to extracts obtained by Soxhlet as the use of heat in extraction by Soxhlet may decompose active constituents of myrrh

\section{Sociodemographic characteristics of schistosomiasis cases}

Most of the cases of mansoniasis were 15-30 years old (47.83\%), males (64\%), illiterates (43.67\%), and also most of the cases practiced true agricultural work $(68.83 \%)$. Some cases are associated with other parasites.

Clinical presentation of the mansoniasis cases before treatment About $43.6 \%$ of the mansoniasis cases were asymptomatic. The most frequent symptoms were easy fatigability $44.17 \%$, abdominal pains $47.5 \%$, abdominal distention $15.5 \%$, and blood in stools, tenesmus, or dysentery among $22.33 \%$. Splenomegaly was found among $8.67 \%$ of the cases, hepatomegaly was about $7.5 \%$, and shrunken liver $4.5 \%$. 
Clinical presentation of mansoniasis cases before and 3 months after treatment

There was a significant clinical improvement as regarding to easy fatigability (reduced from $44.17 \%$ to $5.83 \%$ ), abdominal pains (reduced from $47.5 \%$ to $3.66 \%$ ), abdominal distension (reduced from $15.5 \%$ to $1.16 \%$ ), and blood in stools, tenesmus, or dysentery (reduced from $22.33 \%$ to $0.83 \%$ ).

A statistical test (Chi-square) was calculated for each symptom and was found to be 121.96 in case of easy fatigability, 160.91 in case of abdominal pains, 52.88 in case of in case of abdominal distension, and 87.64 in case of blood in stools, tenesmus, or dysentery; $p=0.000$ in all cases which means that clinical improvement is highly significant ( $p<0.05$ is statistically significant at any value)

The decrease or complete cessation of eggs passing by treatment has been used as criteria for the evaluation of therapeutic activity. The Kato thick smear method is a reliable method for quantitative diagnosis and for the detection of scanty eggs and has also the advantage of simplicity [21]. The percentage cure was determined by determining the number of patients from the 20 patients that did not show eggs in stool. Patients who still had eggs in stool were considered as positive cases.

In the present work, the clinical evaluation of different doses of formulated myrrh extract capsules against different grades of $S$. mansoni infections revealed that the parasitological cure $\%$ as evidence by Kato technique was as follows:

\section{In cases with mild infection}

As expected, the cure percentage increased by increasing the treatment time from 1 to 3 months Fig. 1a. In addition, the number of positive cases decreased by increasing the treatment time, as shown in Fig. 2a. Cure $\%$ of formulated $n$-hexane and alcohol myrrh extracts hard gelatin capsules (150 mg/each, formulae 2 and 5) after 1 and 3 months was $25 \%$ and $100 \%$, respectively, which was equal to that of n-hexane and alcohol myrrh extracts hard gelatin capsules $(200 \mathrm{mg} /$ each, formulae
3 and 6) and more than that of marketed Mirazid soft gelatin capsules (20\% and 95\%), as shown in Fig. 1 a.

On the other hand, cure\% of formulated n-hexane and alcohol myrrh extracts hard gelatin capsules (150 mg/each) after 2 months was $60 \%$ more than that of n-hexane and alcohol myrrh extracts hard gelatin capsules (200 mg/each) and marketed Mirazid soft gelatin capsules (55\%).

As illustrated in Fig. 1, the cure percentage of formulated n-hexane and alcohol myrrh extracts hard gelatin capsules $(100 \mathrm{mg} / \mathrm{each}$, formulae 1 and 4) was lower than that of formulated n-hexane and alcohol myrrh extracts hard gelatin capsules (150 mg/each, formulae 2 and 5) at the different times. In cases which were incompletely cured, there was a significant reduction of infection intensity expressed by number of eggs excreted in stool, as shown in Tables 2 and 3.

\section{In cases with moderate infection}

Increasing the severity of the infection from mild to moderate cases led to a decrease of the cure percentage and increased the number of the positive cases. Cure\% of formulated n-hexane and alcohol myrrh extracts hard gelatin capsules (150 mg/each) after 1 month was 30\% more than that of $n$-hexane and alcohol myrrh extracts hard gelatin capsules (200 mg/each) which was $25 \%$ and equal to that of marketed Mirazid soft gelatin capsules, as shown in Fig. $1 \mathrm{~b}$.

Cure $\%$ of formulated n-hexane and alcohol myrrh extracts hard gelatin capsules (150 mg/each) after 2 months was $55 \%$ equal to that of n-hexane and alcohol myrrh extracts hard gelatin capsules (200 mg/each) and also equal to that of marketed Mirazid soft gelatin capsules.

Cure $\%$ of formulated n-hexane and alcohol myrrh extracts hard gelatin capsules (150 mg/each) after 3 months was $95 \%$ equal to that of n-hexane and alcohol myrrh extracts hard gelatin capsules (200 mg/each) and more than that of marketed Mirazid soft gelatin

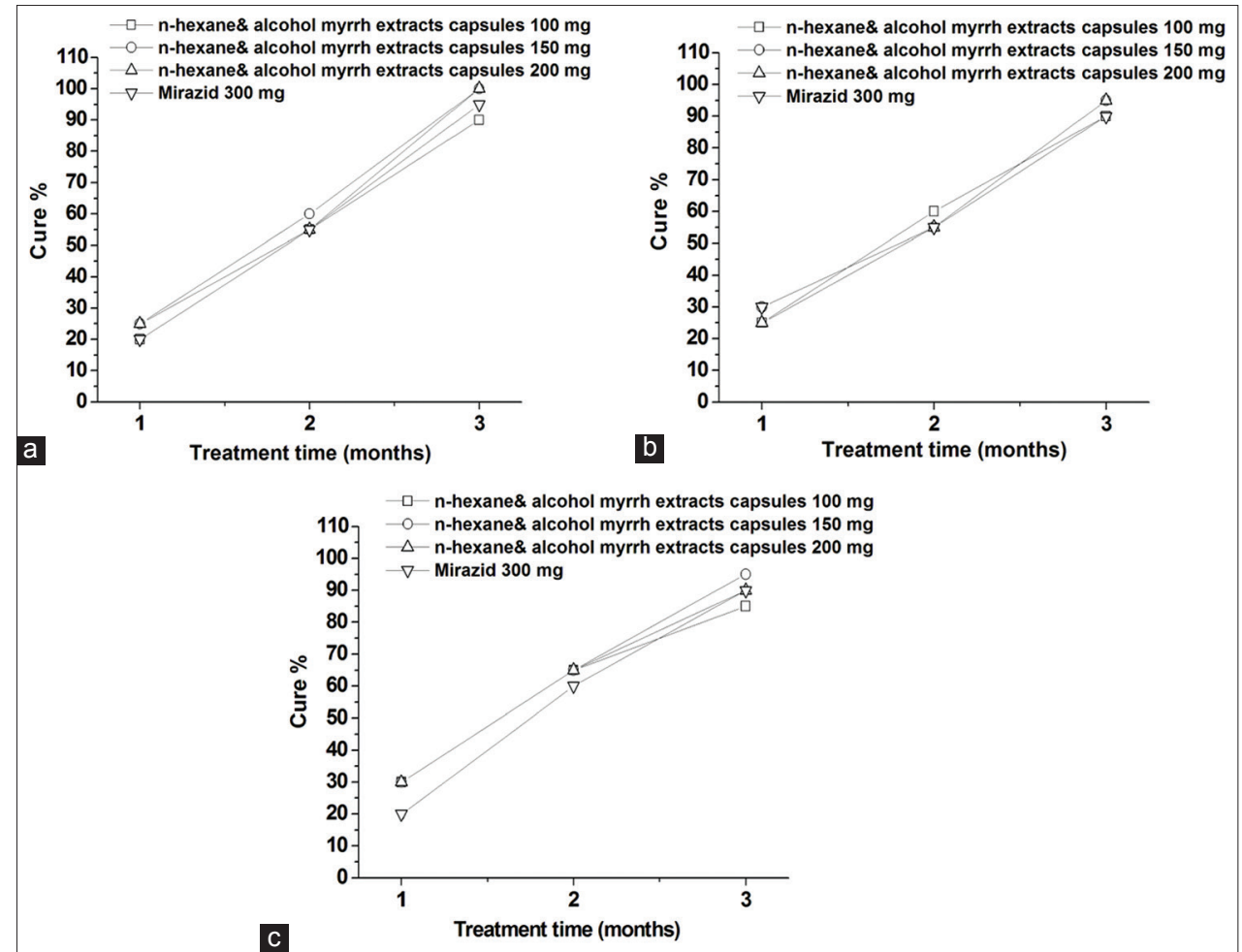

Fig. 1: Cure \% of Schistosoma mansoniasis infected cases after treatment by n-hexane and alcohol myrrh extract capsules; (a) mild $S$. mansoniasis infected cases; (b) moderate $S$. mansoniasis infected cases; (c) heavy $S$. mansoniasis infected cases 


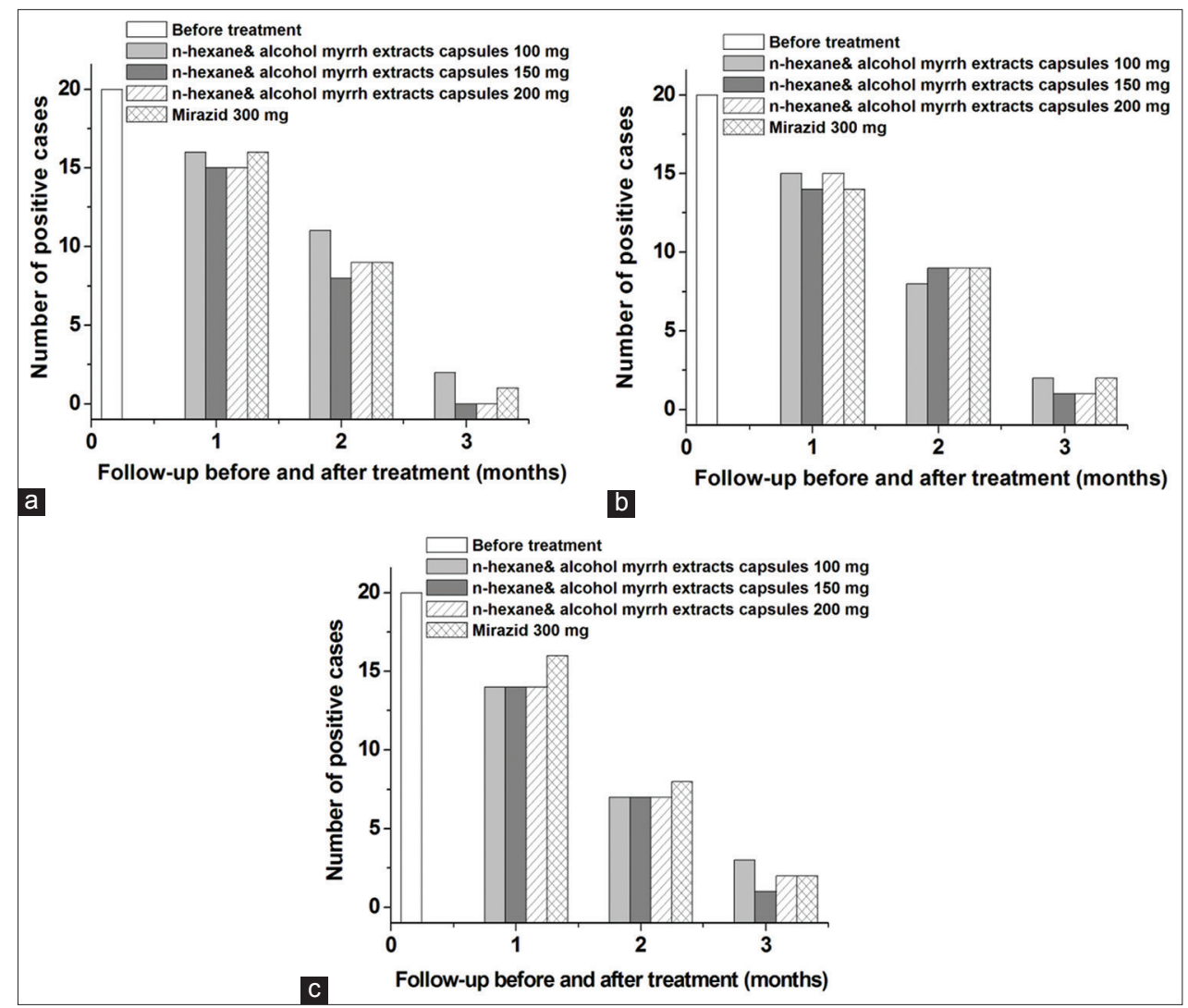

Fig. 2: Relation between number of Schistosoma mansoniasis cases and follow-up before and after treatment by n-hexane and alcohol myrrh extract capsules; (a) mild $S$. mansoniasis infected cases; (b) moderate S. mansoniasis infected cases; (c) heavy S. mansoniasis infected cases

Table 2: Reduction of intensity of infection of $S$. mansoniasis cases which were still positive 1, 2, and 3 months after treatment by n-hexane and alcohol myrrh extract capsules

\begin{tabular}{|c|c|c|c|c|c|}
\hline \multirow[t]{2}{*}{ Type of infection } & \multirow[t]{2}{*}{ Treatment formula } & \multirow[t]{2}{*}{ Time (months) } & \multicolumn{2}{|c|}{ Intensity $(\bar{X} \pm S D)$} & \multirow[t]{2}{*}{ t-test } \\
\hline & & & Pre-treatment & Post-treatment & \\
\hline \multirow[t]{9}{*}{ Mild S. mansoniasis } & $\mathrm{F} 1$ and $\mathrm{F} 4$ & 1 & $79.88 \pm 15.25$ & $41.38 \pm 10.26$ & 8.379 \\
\hline & & 2 & $87.44 \pm 14.88$ & $25.56 \pm 7.47$ & 11.155 \\
\hline & & 3 & $96.50 \pm 4.95$ & $19.50 \pm 0.71$ & 21.779 \\
\hline & $\mathrm{F} 2$ and $\mathrm{F} 5$ & 1 & $79.07 \pm 11.96$ & $48.27 \pm 11.77$ & 7.109 \\
\hline & & 2 & $80.25 \pm 14.87$ & $27.88 \pm 9.99$ & 8.269 \\
\hline & & \multicolumn{4}{|c|}{ After 3 months, cure $\%$ was $100 \%$ (number of positive cases $=0$ cases) } \\
\hline & $\mathrm{F} 3$ and $\mathrm{F} 6$ & 1 & $83.73 \pm 11.85$ & $53.47 \pm 13.00$ & 6.662 \\
\hline & & 2 & $87.00 \pm 11.94$ & $30.33 \pm 6.75$ & 12.399 \\
\hline & & \multicolumn{4}{|c|}{ After 3 months, cure $\%$ was $100 \%$ (number of positive cases $=0$ cases) } \\
\hline \multirow[t]{9}{*}{ Moderate $S$. mansoniasis } & $\mathrm{F} 1$ and $\mathrm{F} 4$ & 1 & $216.13 \pm 42.70$ & $115.40 \pm 45.44$ & 6.257 \\
\hline & & 2 & $244.25 \pm 30.46$ & $68.75 \pm 13.41$ & 14.915 \\
\hline & & 3 & $284.00 \pm 1.41$ & $31.00 \pm 12.73$ & 27.939 \\
\hline & $\mathrm{F} 2$ and F5 & 1 & $224.71 \pm 34.93$ & $144.14 \pm 46.71$ & 5.169 \\
\hline & & 2 & $230.78 \pm 37.82$ & $83.33 \pm 24.07$ & 9.867 \\
\hline & & \multicolumn{4}{|c|}{ After 3 months, cure $\%$ was $95 \%$ (number of positive cases $=1$ case) } \\
\hline & $\mathrm{F} 3$ and F6 & 1 & $215.73 \pm 41.88$ & $125.07 \pm 42.43$ & 5.890 \\
\hline & & 2 & $226.56 \pm 23.50$ & $68.11 \pm 17.12$ & 16.348 \\
\hline & & \multicolumn{4}{|c|}{ After 3 months, cure $\%$ was $95 \%$ (number of positive cases $=1$ case) } \\
\hline \multirow[t]{9}{*}{ Heavy S. mansoniasis } & $\mathrm{F} 1$ and $\mathrm{F} 4$ & 1 & $406.64 \pm 28.36$ & $160.57 \pm 28.47$ & 23.097 \\
\hline & & 2 & $406.64 \pm 28.36$ & $160.57 \pm 28.47$ & 39.897 \\
\hline & & 3 & $413.33 \pm 25.42$ & $35.00 \pm 21.07$ & 19.845 \\
\hline & $\mathrm{F} 2$ and $\mathrm{F} 5$ & 1 & $395.57 \pm 47.93$ & $213.00 \pm 39.17$ & 11.035 \\
\hline & & 2 & $407.57 \pm 53.33$ & $129.57 \pm 66.90$ & 8.597 \\
\hline & & \multicolumn{4}{|c|}{ After 3 months, cure $\%$ was $95 \%$ (number of positive cases $=1$ case) } \\
\hline & F3 and F6 & 1 & $379.36 \pm 41.17$ & $192.29 \pm 28.36$ & 14.001 \\
\hline & & 2 & $401.43 \pm 27.02$ & $116.71 \pm 26.03$ & 20.078 \\
\hline & & 3 & $377.00 \pm 18.38$ & $40.00 \pm 26.87$ & 14.638 \\
\hline
\end{tabular}


Table 3: Reduction of intensity of infection of $S$. mansoniasis cases which were still positive 1, 2, and 3 months after treatment by Mirazid capsules $300(\mathrm{mg})$

\begin{tabular}{|c|c|c|c|c|}
\hline \multirow[t]{2}{*}{ Type of infection } & \multirow[t]{2}{*}{ Time (months) } & \multicolumn{2}{|c|}{ Intensity $(\bar{X} \pm \mathrm{SD})$} & \multirow[t]{2}{*}{ t-test } \\
\hline & & Pre-treatment & Post-treatment & \\
\hline \multirow[t]{2}{*}{ Mild S. mansoniasis } & 1 & $78.38 \pm 16.12$ & $46.31 \pm 15.79$ & 5.683 \\
\hline & \multicolumn{4}{|c|}{ After 3 months, cure $\%$ was $95 \%$ (number of positive cases $=1$ case) } \\
\hline \multirow[t]{3}{*}{ Moderate S. mansoniasis } & 1 & $287.86 \pm 43.16$ & $117.71 \pm 38.95$ & 5.802 \\
\hline & 2 & $213.89 \pm 42.08$ & $59.56 \pm 19.17$ & 10.013 \\
\hline & 3 & $210.00 \pm 49.50$ & $25.00 \pm 2.83$ & 5.277 \\
\hline \multirow[t]{3}{*}{ Heavy S. mansoniasis } & 1 & $407.50 \pm 47.05$ & $214.43 \pm 37.12$ & 12.054 \\
\hline & 2 & $404.00 \pm 50.43$ & $119.63 \pm 38.35$ & 12.707 \\
\hline & 3 & $397.00 \pm 18.38$ & $60.00 \pm 26.87$ & 14.638 \\
\hline
\end{tabular}

S. mansoniasis: Schistosoma mansoniasis, SD: Standard deviation

capsules (90\%). Fig. 2b shows that the number of positive cases decreased by increasing the treatment time from 1 to 3 months.

As mentioned before with the mild infections cases which were incompletely cured, there was a significant reduction of infection intensity expressed by number of eggs excreted in stool, as shown in Tables 2 and 3.

\section{In cases with heavy infection}

As expected, the cure percentage increased by increasing the treatment time from 1 to 3 months. In addition, the number of positive cases decreased by increasing the treatment time, as shown in Figs. 1 and 2. On the contrary, increasing the severity of the infection from mild to heavy cases led to a decrease of the cure percentage and increased the number of positive cases. On the other hand, cure\% of formulated n-hexane and alcohol myrrh extracts hard gelatin capsules (150 mg/each) after 3 months was 95\% more than that of n-hexane and alcohol myrrh extracts hard gelatin capsules $(200 \mathrm{mg} /$ each) and marketed Mirazid soft gelatin capsules (90\%), as shown in Fig. 1c.

Cure $\%$ of formulated n-hexane and alcohol myrrh extracts hard gelatin capsules (150 mg/each) after 1 and 2 months were $30 \%$ and $65 \%$, respectively, equal to that of $n$-hexane and alcohol myrrh extracts hard gelatin capsules (200 mg/each) and more than that of marketed Mirazid soft gelatin capsules (20\% and 60\%).

In all types of $S$. mansoni infection (mild, moderate, and heavy), it is clear that the efficacy of n-hexane and alcohol myrrh extracts hard gelatin capsules (150 mg/each) was higher than or equal to Mirazid soft gelatin capsules with respect to the cure percentage, number of positive cases, and infection intensity expressed by number of eggs excreted in stool; $\mathrm{p}=0.000$ in all cases which means that clinical improvement is highly significant ( $p<0.05$ is statistically significant at any value). This could be attributed to the higher ability of n-hexane in the extraction of furanosesquiterpene which is the main constituent of myrrh [22]. Furanosesquiterpene is a volatile oil which is highly soluble in organic solvents such as n-hexane. On the other hand, alcohol may extract the hydrophilic constituent from myrrh and thus increases the efficiency of these hard gelatin capsules in comparison with marketed Mirazid soft gelatin capsules.

From the present work, there was a significant clinical improvement in the cure $\%$ as regard to easy fatigability, abdominal pains, and distension. There was complete disappearance of the symptoms of blood in stool, tenesmus, or dysentery after treatment by all doses. All doses and forms were well tolerated by all patients without side effects.

In cases with incomplete cure, there was a marked reduction in intensity of infection expressed by number of eggs excreted in stool. This is of utmost public health significance in decreasing the spread and intensity of infection.

\section{CONCLUSION}

Myrrh extract is a safe, potent, and effective treatment of schistosomiasis and can be used in community-based prevention and control thereof. Hard gelatin capsules of myrrh extract (mixed doses) are more effective and economic as a pharmaceutical dosage form for pharmaceutical manufacturers than Mirazid soft gelatin capsules and with a lower price can reach poor patients which represent the main schistosomiasis patients.

\section{AUTHORS' CONTRIBUTIONS}

Dr. Randa Abdou prepared the myrrh extract and revised the manuscript. Dr. Mohamed Dawoud prepared the hard gelatin capsules of myrrh extract, performed the clinical evaluation of myrrh extracts hard gelatin capsules, and wrote the manuscript.

\section{CONFLICTS OF INTEREST}

The authors report no conflicts of interest. The authors alone are responsible for the content and writing of this article.

\section{REFERENCES}

1. El-Khoby T, Galal N, Fenwick A, Barakat R, El-Hawey A, Nooman Z, et al. The epidemiology of schistosomiasis in Egypt: Summary findings in nine governorates. Am J Trop Med Hyg 2000;62:88-99.

2. Dias LC, Pedro RJ, Rigo E, Goto MM, Mafra GL. A human strain of Schistosoma mansoni resistant to schistosomicides. Rev Saude Publica 1978; $12: 110$.

3. Gryseels B, Polderman AM. Morbidity, due to Schistosoma mansoni, and its control in Sub-Saharan Africa. Parasitol Today 1991;7:244-8.

4. Fallon PG, Mubarak JS, Fookes RE, Niang M, Butterworth AE, Sturrock RF, et al. Schistosoma mansoni: Maturation rate and drug susceptibility of different geographic isolates. Exp Parasitol 1997;86:29-36.

5. Van der Werf MJ, de vlas SJ, Brooker S, Looman CW, Nagelkerke NJ, Habbema JD, et al. Quantification of clinical morbidity associated with schistosome infection in Sub-Saharan Africa. Acta Trop 2003;86:125-39.

6. Scott J. The incidence and distribution of the human schistosomiasis in Egypt. Am J Hyg 1937;25:566-614.

7. El-Sharkawy A, El-Toukhy M, Abdel-Rahman SZ, El-Kholy Z, Farag H, El-Zoghby S, et al. An experimental study on the effect of praziquantel and oltipraz on some lysosomal enzymes. J Trop Med Hyg 1993;96:28-34.

8. Herrera LA, Ostrosky-Wegman P, Montero R, Rojas E, Gonsebatt ME, Schiffmann D. Evaluation of the carcinogenic and genotoxic potential of praziquantel in the syrian hamster embryo cell transformation assay. Mutat Res 1994;305:175-80.

9. Rosenkranz HS, Zhang YP, Klopman G. Studies on the potential for genotoxic carcinogenicity of fragrances and other chemicals. Food Chem Toxicol 1998;36:687-96.

10. Rosenkranz HS, Zhang YP, Macina OT, Mattison DR, Klopman G. Human developmental toxicity and mutagenesis. Mutat Res 1998:422:347-50.

11. Montero R, Gonsebatt ME, Herrera LA, Rojas E, Ostrosky-Wegman P. The HPRT short-term assay in monitoring individuals exposed to genotoxic agents. Environ Health Perspect 1993;101 Suppl 3:135-8. 
12. Kheir WM, Elsheikh HA, Hapke HJ. The effect of praziquantel on the activities of some drug-metabolizing hepatic enzymes in rabbits. Dtsch Tierarztl Wochenschr 1995;102:84-6.

13. Tonelli SM, Goulart EM, Tonelli E, Coelho PM. Lethal effect of oxamniquine and praziquantel on mice experimentally infected with Schistosoma mansoni. Rev inst med trop sao paulo 1995;37:361-3.

14. Watt G, White NJ, Padre L, Ritter W, Fernando MT, Ranoa CP, et al. Praziquantel pharmacokinetics and side effects in Schistosomajaponicuminfected patients with liver disease. J Infect Dis 1988;157:530-5.

15. Al-Harbi MM, Qureshi S, Ahmed MM, Rafatullah S, Shah AH. Effect of Commiphora molmol (oleo-gum-resin) on the cytological and biochemical changes induced by cyclophosphamide in mice. Am J Chin Med 1994;22:77-82.

16. Massoud A, El Sisi S, Salama O, Massoud A. Preliminary study of therapeutic efficacy of a new fasciolicidal drug derived from Commiphora molmol (Myrrh). Am J Trop Med Hyg 2001;65:96-9.

17. Massoud AA, Hussein HM, Reda MA, El-Wakil HS, Maher KM, Mahmoud FS. Schistosoma mansoni egg specific antibodies and circulating antigens: assessment of their validity in immunodiagnosis of schistosomiasis. J Egypt Soc Parasitol 2000;30:903-16.

18. Hashem F, Massoud A, Melokheya A, Emad H, Badr K, Dawoud M. Formulation and clinical efficacy of myrrh extract in hard gelatin capsules. J Biol Active Prod From Nat 2013;3:72-86.

19. Michelson MK, Azziz FA, Gamil FM, Wahid AA, Richards FO, Juranek DD, et al. Recent trends in the prevalence and distribution of schistosomiasis in the nile delta region. Am J Trop Med Hyg 1993;49:76-87.

20. Katz N, Chaves A, Pellegrino J. A simple device for quantitative stool thick-smear technique in Schistosomiasis mansoni. Rev Inst Med Trop Sao Paulo 1972;14:397-400.

21. Martin LK, Beaver PC. Evaluation of kato thick-smear technique for quantitative diagnosis of helminth infections. Am J Trop Med Hyg 1968; 17:382-91.

22. ELAshry ER, Salama O. Colorimetric determination of crude powdered myrrh, purified myrrh extract, oily fraction, and its pharmaceutical dosage forms. Spectrosc Lett 2002;35:183-97. 